\title{
Ultra-High Strength Ti Grade 4 Prepared by Intensive Plastic Deformation
}

Filip Průša ${ }^{1}$, Adriana Bernatiková ${ }^{1,2}$, Jan Palan $^{3}$

${ }^{1}$ Faculty of Chemistry and Technology, University of Chemistry and Technology Prague, Technická 5, 16628 Prague 6. Czech Republic. E-mail: prusaf@vscht.cz

${ }^{2}$ Institute of Physics of the Czech Academy of Sciences, Na Slovance 1999/2, 18221 Prague 8. Czech Republic.

${ }^{3}$ Comtes FHT a.s., Průmyslová 995, 33441 Dobřany. Czech Republic

The aims of the present work were focused on evaluation of the processing steps on the microstructure and mechanical properties of titanium grade 4 material. The rod was subjected to Conform SPD processing which combined multiple passes throughout the ECAP with consequential cold working which reduced the sectional area by $\mathbf{8 0 \%}$. The microstructure of the prepared material was well-refined showing presence of phases whith sub-micrometre dimensions. The mechanical properties of these materials were evaluated by hardness measurements and by compressive strees-strain tests and by tensile stress-strain tests, both performed at laboratory temperature. The highest hardness of $330 \pm 6 \mathrm{HV} 1$ was achieved by the material prepared by Conform SPD process while the same material in its initial state showed hardness of only $170 \pm 4 \mathrm{HV}$. The Conform SPS process also increased the compressive yield strength and compressive strength reaching $1033 \mathrm{MPa}$ and $1608 \mathrm{MPa}$, respectively, while the tensile test resulted in yield strength and ultimate tensile strength of $1136 \mathrm{MPa}$ and $1142 \mathrm{MPa}$, respectively.

Keywords: Ti grade 4, equal channel angular pressing, cold working, microstructure, mechanical properties

\section{Acknowledgement}

The research was supported by the Czech Science Foundation (project no. P108/12/G043).

\section{References}

[1] BARILE, C., CASAVOLA, C.; et al. (2016) Acoustic sources from damage propagation in Ti grade 5. In: Measurement, Vol. 91, No., pp. 73-76.

[2] EFTEKHARI, M., FARAJI, G.; et al. (2017) Processing and characterization of nanostructured Grade 2 Ti processed by combination of warm isothermal ECAP and extrusion. In: Materials Science and Engineering: A, Vol. 703, No., pp. 551-558.

[3] ASTARITA, A., PRISCO, U. (2017) Tensile properties of a hot stretch formed Ti-6Al-4V alloy component for aerospace applications. In: Manufacturing Technology, Vol. 17, No. 2, pp. 141-147.

[4] NAZARI, K.A., HILDITCH, T.; et al. (2016) Functionally graded porous scaffolds made of Ti-based agglomerates. In: Journal of the Mechanical Behavior of Biomedical Materials, Vol. 63, No., pp. 157-163.

[5] FINTOVÁ, S., ARZAGHI, M.; et al. (2017) Fatigue crack propagation in UFG Ti grade 4 processed by severe plastic deformation. In: International Journal of Fatigue, Vol. 98, No., pp. 187-194.

[6] STOLYAROV, V.V., ZEIPPER, L.; et al. (2008) Influence of post-deformation on CP-Ti processed by equal channel angular pressing. In: Materials Science and Engineering: A, Vol. 476, No. 1, pp. 98-105.

[7] SITDIKOV, V.D., ALEXANDROV, I.V. (2013) Computer modeling of texture formation processes in Ti Grade 4 during continuous equal channel angular pressing. In: Computational Materials Science, Vol. 76, No., pp. 6571.

[8] SEMENOVA, I.P., POLYAKOV, A.V.; et al. (2017) Mechanical behavior and impact toughness of the ultrafinegrained Grade 5 Ti alloy processed by ECAP. In: Materials Science and Engineering: A, Vol. 696, No., pp. 166173.

[9] VALIEV, R.Z., LANGDON, T.G. (2006) Principles of equal-channel angular pressing as a processing tool for grain refinement. In: Progress in Materials Science, Vol. 51, No. 7, pp. 881-981.

[10] PRŮŠA, F., VOJTECH, D.; et al. (2015) Mechanical alloying: A way how to improve properties of aluminium alloys. In: Manufacturing Technology, Vol. 15, No. 6, pp. 1036-1043. 